\title{
Practical Teaching of "Health Management for Relatives and Friends" Based on Comprehensive Quality Training of Medical Students
}

\author{
Xia Wenfang ${ }^{1}$, Liu Yaling ${ }^{2}$, Li Hui ${ }^{2}$, Ji Xiangnian ${ }^{3}$, * \\ ${ }^{1}$ Department of Endocrinology, Union Hospital, Tongji Medical College, Huazhong University of Science and Technology, Wuhan, China \\ ${ }^{2}$ Education Department, Union Hospital, Tongji Medical College, Huazhong University of Science and Technology, Wuhan, China \\ ${ }^{3}$ Hospital Administration, Union Hospital, Tongji Medical College, Huazhong University of Science and Technology, Wuhan, China
}

\section{Email address:}

2457414119@qq.com (Ji Xiangnian)

${ }^{*}$ Corresponding author

\section{To cite this article:}

Xia Wenfang, Liu Yaling, Li Hui, Ji Xiangnian. Practical Teaching of "Health Management for Relatives and Friends" Based on Comprehensive Quality Training of Medical Students. Clinical Medicine Research. Vol. 9, No. 4, 2020, pp. 69-73.

doi: 10.11648/j.cmr.20200904.11

Received: June 30, 2020; Accepted: July 13, 2020; Published: July 23, 2020

\begin{abstract}
In the context of the development of medical science and the transformation of medical models, higher requirements are placed before physicians with respect to comprehensive quality. Training for comprehensive quality requires strengthening of medical education. In the current training environment, it is difficult for traditional medical colleges and universities to meet this demand. Our school takes an approach that places the medical students at the center. We are conducting research on strategies and methods of the practical teaching model called "health management for relatives and friends (HMRF)." This entails managing the health of medical students' relatives and friends, establishing a network platform, and organically combining the network platform with traditional teaching. After 6 years of exploration and implementation, medical students effectively improved their autonomous learning abilities and augmented occupational qualities such as clinical thinking, doctor-patient communication, information collection, and clinical decision-making. They did this by role-playing, practicing progressive humanistic care, and transferring educational practice to clinical practice. Practical teaching of health management for relatives and friends is a new, effective, and simple training model to enhance multidimensional qualities of medical students.
\end{abstract}

Keywords: Medical Education, Health Management, Humanistic Concern, Comprehensive Quality, Medical Students, Clinical Practice

\section{Introduction}

Coincident with social development and the growth of human awareness of their own health, academic medicine has been placing higher requirements on medical students. Particularly in such developing countries such as China, where there has been steady improvement of the economy and standards of living, human demands for health are also transforming [1]. Currently, medical goals are transforming from diagnosis and treatment of diseases to disease prevention and diagnosis. Treatment centers are transforming from large-scale hospitals to communities [2], and this requires that medical students possess comprehensive professional qualities adapted to social needs. The World Federation for Medical
Education proposed in "The Most Fundamental Requirements for Global Medical Education" [3, 4] that medical graduates cultivated by medical colleges and universities across the world must have basic qualities in the following seven aspects: medical professional values, attitudes, behavior, ethics, rudimentary knowledge of medical science, exchange and communication skills, clinical skills, knowledge of group health and healthcare systems, information management, and critical thinking and research skills. Against this background, China formulated "Opinions on Implementing Education and Cultivation of Excellent Doctors," [5] which proposed strengthening the comprehensive qualities of medical students and implementing education reform toward "all-round development with a priority to moral education and an 
emphasis on abilities."

It is difficult for the current traditional medical education model to adapt to the social demand for such broad abilities [6]. Cultivation of comprehensive qualities requires innovative medical practice models. To explore effective methods and strategies for cultivating comprehensive qualities, our school started to implement the teaching program of health management for relatives and friends of medical students in March 2013. Medical students established records for their relatives and friends as the medium to progressively conduct health management for relatives and friends with medical students as the main part. In this project, the existing medical course system solved the problem of lack of practice opportunities, raising health management awareness of medical students in practice, and permitting students to study the health management literature, all while improving their comprehensive occupational qualities.

\section{Implementation of the Project of Health Management for Relatives and Friends}

\subsection{Establishing Health Records for Relatives and Friends}

The project uses health records of medical students' relatives and friends as the medium of education. Clinical medicine majors were selected and each was required to establish health records for their respective relatives and friends from his or her freshman years. The subjects included both sick relatives and friends and sub-healthy and healthy relatives and friends. The health records of relatives and friends were established in the following manner: With the residents' health records as the template, the medical students comprehensively collected the health information from three of their different ages relatives and friends by contacting them by phone or internet during their vacations at home or during study at school. Relatives and friends with completed health examination information were selected to the greatest extent possible. Then, health examination information and/or diagnosis and treatment medical records were collected to complete preliminary paper-based or electronic health records. Subsequently, the medical students from their sophomore years to their fifth year of college continuously tracked and managed the health conditions of their relatives and friends with health records to gradually form complete health records. By December 2019, over 612 students majoring in clinical medicine (five-year and eight-year), medical imaging, medical laboratory science, and others participated in the project, establishing and tracking heath records for their relatives and friends.

\subsection{Setting up a Steering Group of Teaching Practice for Health Management for Relatives and Friends}

During the process of project implementation, a steering group of teaching practice for health management for relatives and friends was established. The group was composed of managerial teaching staff, clinical professional teachers, and core students.
The professional teachers were clinical physicians with teaching qualifications from large medical institutions. The core students were medical students in higher grades, particularly at the clinical practice stage. The sick relatives and friends of the medical students were grouped by disease types and the relatives and friends with multiple types of diseases were managed by general practice professional groups. The steering group provided a review of the professional knowledge and the students provided opinions on diagnosis and treatment of diseases for relatives and friends. For example, the students would offer diagnosis and treatment advice to the patients with diabetes complicated by coronary heart disease under the guidance of doctors of the endocrinology department and cardiovascular department. Publicity and education work of disease prevention and health knowledge was conducted for the groups of sub-healthy and healthy relatives and friends. For example, under the guidance of professional teachers of the departments of gynecology and obstetrics and pediatrics, the medical students educated the pregnant and delivering women regarding problems such as breastfeeding and healthcare, as well as scientific feeding of infants and young children.

\subsection{Heath Management Practice with the Students as the Main Part}

After establishing health records for the relatives and friends, the students summarized their health demands, collated and processed them into main problems to be solved, and submitted them to the network information exchange platform according the template. All students and clinical physicians within the platform discussed the relevant problems of the case with respect to collection of medical history, diagnosis and treatment, prevention and recovery, medical costs, choices of seeking treatment, humanistic care, and disease prognosis, all in real time. The specific steps are described below. The students in higher grades served as the managers of the steering group of teaching practice of health management for relatives and friends collected the cases on a weekly basis and organized discussion on the cases and difficult problems submitted by the students. The discussion process was characterized by enlightenment. The teachers led the students to study autonomously so as to cultivate their clinical thinking skills rather than directly giving them the diagnosis and treatment schemes. Meanwhile, typical cases of the students' relatives and friends were selected to organize a Problem Based Learning (PBL) class for discussion-based teaching. The clinical teachers exchanged with the students via the teaching platform, clinical practice platform, and the network information platform, implementing multi-level hybrid cooperative PBL teaching models [7], and providing timely guidance so that the students could solve various problems during the process of health management.

\subsection{Continuous Update and Feedback of Health Information}

The medical students were responsible for the work of update and feedback of the information on health 
management. It was required that each record should be continuously tracked less than 2 years from the day of record establishment. The information on health records of patients with chronic diseases and the sub-healthy and healthy relatives and friends was to be updated quarterly. Data on special cases of patients with critical diseases, women during pregnancy, and the like were updated in real time according to the actual situation. Information was collected by phone or internet during school terms and the students communicated with their relatives and friends during winter and summer vacations.

Based on autonomous learning, the students sorted out and analyzed the network consultation opinions, clinical expert advice, and PBL case discussion results to develop treatment plans. These were recorded in the health records. After the plans were reviewed by the clinical physicians in various steering groups, the students sent the advice to their relatives and friends by mail and suggested they seek medical advice to improve their health behavior. The students followed up the subsequent conditions of their relatives and friends and adjusted treatment recommendations in a timely manner. The relatives and friends were encouraged to document their diagnosis and treatment processes, mental states, and expenses with respect to their health conditions from the perspective of patients as reference data for the benefit medical student learning.

\section{Implementation Effects of the Teaching Program of Health Management for Relatives and Friends}

Since March 2013 when the project was implemented, a total of 612 medical students participated in the teaching program and established 1786 health records for the relatives and friends. On the network platform, approximately ten cases were discussed each week. The students and their relatives and friends obtained benefits in many aspects by implementing the teaching program.

\subsection{Cultivating Comprehensive Qualities in Holistic Manner}

The students collected information, summarized the medical problems in daily life, and identified the appropriate solutions by means of diversified learning. Such a practice model dominated by students motivated the students' potential in autonomous learning, investigative learning, and team learning. The content of the case data of health management for relatives and friends was substantial, integrating various basic skills of clinical medicine. The students were required to become familiar with key points of inquiry and to obtain a solid command of specialized knowledge on internal medicine, surgery, obstetrics and gynecology, and pediatrics, as well as prevention, psychology, health economy, and others. Compared with the traditional education model, the students who participated in the training of the HMRF program continuously expanded their scope of knowledge and improved their practical knowledge. Compare the graduation objective structured clinical examination (OSCE) scores, a randomized controlled study found that 68 clinical medicine students in the HMRF group had significantly better history-taking, medical record writing and case analysis ability than other 68 students in the control group in the same class (Table 1). And the practice of health management for relatives and friends fully motivated the subjective initiative of the students and cultivated the students' comprehensive qualities from various dimensions in a holistic manner. After one year HMRF program training, 224 medical students conducted a survey among themselves, their friends and relatives, teachers, the survey results showed that the comprehensive quality of the students after HMRF program training improved significantly (Table 2).

Table 1. Comparison of graduation OSCE scores of 136 medical students in Union Hospital, Tongji Medical College, Huazhong University of Science and Technology $(x \pm s)$.

\begin{tabular}{llll}
\hline & Control group $(\mathbf{n = 6 8})$ & HMRF group $(\mathbf{n = 6 8})$ & $\boldsymbol{p}$ \\
\hline History-taking & $84.5 \pm 5.34$ & $90.9 \pm 5.11$ & $<0.05$ \\
Physical examination & $91.2 \pm 4.76$ & $91.7 \pm 5.03$ & $>0.05$ \\
Medical record writing & $85.1 \pm 4.27$ & $91.4 \pm 4.84$ & $<0.05$ \\
Case analysis & $87.0 \pm 3.58$ & $92.2 \pm 4.39$ & $<0.05$ \\
\hline
\end{tabular}

Table 2. The number and proportion of participants in the survey who believe that the HMRF program can improve the Medical Students comprehensive quality.

\begin{tabular}{|c|c|c|c|c|c|c|}
\hline & \multicolumn{2}{|c|}{ Student self-evaluation $(n=224)$} & \multicolumn{2}{|c|}{ Relative evaluation $(n=616)$} & \multicolumn{2}{|c|}{ Teacher evaluation $(n=26)$} \\
\hline & $\mathbf{n}$ & $\%$ & $\mathbf{n}$ & $\%$ & $\mathbf{n}$ & $\%$ \\
\hline Autonomous learning & 213 & 95.1 & 565 & 91.7 & 24 & 92.3 \\
\hline Clinical thinking & 208 & 92.8 & 588 & 95.5 & 24 & 92.3 \\
\hline Doctor-patient communication & 216 & 96.4 & 604 & 98.1 & 25 & 96.1 \\
\hline Strengthen empathy & 211 & 93.8 & 608 & 98.7 & 25 & 96.1 \\
\hline Foster teamwork & 209 & 93.3 & 593 & 96.3 & 23 & 88.5 \\
\hline Scientific research & 203 & 90.6 & 586 & 95.1 & 22 & 84.6 \\
\hline
\end{tabular}




\subsection{Strengthening the Medical Students' Sense of Responsibility and Sense of Occupational Mission}

During the process of establishing records and managing information, the students integrated the knowledge acquired and comprehensively considered the actual conditions of their relatives and friends to make clinical decisions more conducive to their health [8]. The medical students collect medical histories of their relatives and friends and performed physical examinations as clinical physicians, while they were able to experience the feeling of seeking medical advice and understanding the health demands of the patients' family members by managing health of their relatives and friends. And during the continuous role transformation, the medical students strengthened their doctor-patient empathy and communication ability and fully experienced the demands of doctors and patients, thereby laying a solid medical and humanistic foundation for their careers [9].

As a special form of residents' health management, health management for relatives and friends supplemented the existing medical education without community medical education [10]. Strengthening community medical service is the main direction of China's medical reform [11]. The practice of health management for relatives and friends enabled the students to understand the importance and complexity of the primary healthcare service and established the concept of early heath intervention. The implementation of the project of health management for relatives and friends strengthened the medical students' senses of responsibility and sense of occupational mission.

\section{Discussion}

After over 6 years of exploration and implementation, the teaching project of health management for relatives and friends has become an effective practice model for cultivating the comprehensive qualities of the medical students. Compared with general health management projects, this project has the following characteristics: (1) The practice is mainly conducted by the medical students at school. It compensates for deficiencies of the knowledge on health management and community medicine in the existing course system and provides rich practice opportunities for medical students; (2) the objects to be managed are the students' relatives and friends, which effectively solves the problem of difficulties with track and update of records in general health management [12]; (3) the management modes include communication between the students and their relatives and friends, collection of medical histories, making diagnosis, and giving advice regarding treatment, and recommending preventive measures. This form of autonomous learning allows students to gain clinical knowledge while strengthening clinical thinking skills as well as emotional transference the students and their relatives and friends.

All participants benefited from the program. The entire practice process allows for arousal of learning interest and all-round development of the students' professional qualities. The relatives and friends subjected to health management raised their own awareness of healthcare and obtained specific medical advice, thereby achieving the goals of promoting the public health and improving quality of life [13, 14]. The clinical teachers expanded their teaching methods, enriched teaching examples and conducted teaching based on the students' actual demands during the process of guiding and assisting the students.

\section{Conclusion}

As a novel extracurricular way of learning, the health management for relatives and friends enables students in lower grades to obtain opportunities to understand clinical practice at an early stage. It can help students to develop proper professional attitudes and stimulate their own initiative during practice [15]. The continuous track management enables medical students to remarkably improve their concepts of overall prevention, diagnosis and treatment, and recovery. It also strengthens emotional exchanges between the medical students and their relatives and friends. Finally, it provides an effective approach to improving clinical thinking skills, practice skills communication abilities, and humanistic care skills. The teaching model is simple and conducive to strengthening of the concept of nationwide prevention and promotion of normalization of clinical diagnosis and treatment.

\section{Acknowledgements}

We thank all the participants in this study who cooperated for "Health Management for Relatives and Friends" based medical practice education. We are grateful for Dr. Xie Jun, MD from University Hospital, Huazhong University of Science and Technology who provided significant feedback for this study. We want to express our gratitude to Dr. Zhao Ye, MD, Ph.D. from Cancer Branch, Union Hospital, Tongji Medical College, Huazhong University of Science and Technology who provided precious comments to validate this study.

\section{Authors' Contributions}

The design of this study was initiated by the corresponding author (JXN), the first author (XWF) together with the second (LYL), third (LH) who are all involve in the development of this program in their medical institutions. The first draft of this study was written by the first authors (XWF) and commented by the other authors until the final form agreed. The corresponding author (JXN) provided scientific medical education review since the beginning of this study. All authors provided consent to publish this study to the Clinical Medicine Research journal. All authors read and approved the final manuscript. 


\section{Funding}

This study is funded by Teaching and Research Project Grants (2014 Major, 2015-83, 2018-41) Huazhong University of Science; Higher Medical Education Clinical Teaching Research Grants, Clinical Teaching Research Center Project, Ministry of Education, China, (Edu-CR-2016-1-5); Medical Education Research Grants, Medical Education Branch of Chinese Medical Association and Medical Education Professional Committee of Chinese Higher Education Society (2018A-N05084).

\section{References}

[1] Lam TP, Lam YYB. Medical education reform: the Asian experience. Acad Med. 2009; 84: 1313-1317.

[2] WHO. Primary health care is now more than ever. Geneva: The World Health Report, WHO; 2008.

[3] Basic Medical Education. 2003. WFME global standards for quality improvement. Copenhagen: WFME Office.

[4] Basic Medical Education. 2012. WFME global standards for quality improvement. The 2012 Revision. Copenhagen: WFME Office.

[5] Chinese Ministry of Education, Ministry of Health. Opinions on implementing education and cultivation of excellent doctors [EB/OL]. [2012-05-07]. http://www.moe.gov.cn/srcsite/A08/moe_740/s7952/201205/t 20120507 166950.html.

[6] Sean Tackett, Janet Grant, Kristin Mmari. Designing an evaluation framework for WFME basic standards for medical education [J], Medical Teacher, 201638 (3):, 291-296, DOI: 10.3109/0142159X.2015.1031737

[7] Yan-Jia C, Chun-Shui L, Zheng H, Jian P, Xin-Fu H. On Problem-based Learning in Improving Doctor-patient
Communication Competency of Medical Students during Clinical Practice [J]. medical education research and practice, 2018; 26 (3): 422-424.

[8] Janevic M R, Rosland A M, Wiitala W, Connell C M, Piette J D. Providing support to relatives and friends managing both chronic physical illness and depression: The views of a national sample of U.S. adults [J]. Patient Education \& Counseling, 2012, 89 (1): 191-198.

[9] Koponen J, Pyorala E, Isotalus P. Comparing three experiential learning methods and their effect on medical students' attitude to learning communication skills. Med Teach. 2012; 34: e198207.

[10] Claramita, M., Setiawati, E. P., Kristina, T. N. et al. Community-based educational design for undergraduate medical education: a grounded theory study. BMC Med Educ 19, 258 (2019).

[11] Bitton A, Ratcliffe HL, Veillard JH, Kress DH, Barkley S, Kimball M, et al. Primary health care as a foundation for strengthening health systems in low- and middle-income countries. J Gen Intern Med. 2017; 32: 566-71. doi: 10.1007/s11606-016-3898-5. 2019; 19 (1): 258-267. Published 2019 Jul 11. doi: 10.1186/s12909-019-1643-6.

[12] Walraven G. The 2018 Astana Declaration on Primary Health Care, is it useful?. J Glob Health. 2019; 9 (1): 010313. doi: 10.7189/jogh.09.010313

[13] Oswald N, Alderson T, Jones S. Evaluating primary care as base for medical education: the report of the Cambridge community-based clinical course. Med Educ. 2001; 35: 782-8.

[14] Mboi N, Surbakti IM, Trihandini I, et al. On the road to universal health carein Indonesia, 1990-2016: a systematic analysis for the Global Burden of Disease Study 2016. Lancet. 2018; 392: 581-91.

[15] Sherbino J, Frank JR, Snell L. Defining the key roles and competencies ofthe clinician-educator of the 21 st century: a national mixed-methods study. Acad Med. 2014; 89: 783-789. 